Faculty \& Staff Scholarship

1999

Facility Layout of Irregular-shaped Departments using a Nested Approach

Alan McKendall

James Noble

Cerry Klein

Follow this and additional works at: https://researchrepository.wvu.edu/faculty_publications

Part of the Operations Research, Systems Engineering and Industrial Engineering Commons 
This article was downloaded by:[West Virginia University]

On: 31 May 2007

[West Virginia University]

Access Details: [subscription number 770488798]

Publisher: Taylor \& Francis

Informa Ltd Registered in England and Wales Registered Number: 1072954

Registered office: Mortimer House, 37-41 Mortimer Street, London W1T 3J H, UK

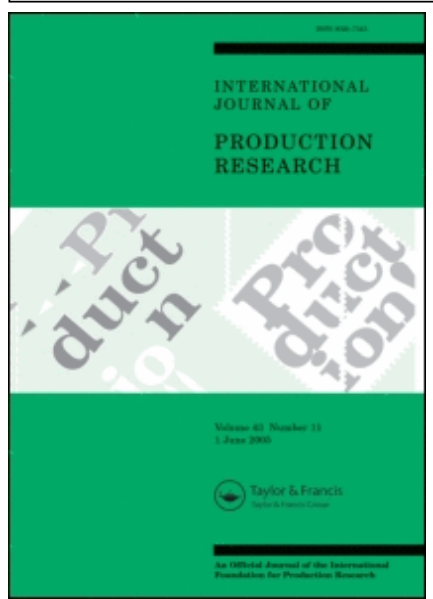

\section{International J ournal of P roduction Research}

Publication details, including instructions for authors and subscription information: http://www.informaworld.com/smpp/title $\sim$ content=t713696255

\section{Facility layout of irregular-shaped departments using a} nested approach

A. R. Mckendall; J. S. Noble; C. M. Klein

To cite this Article: Mckendall, A. R., Noble, J . S. and Klein, C. M. , 'Facility layout of irregular-shaped departments using a nested approach', International J ournal of

Production Research, 37:13, 2895 - 2914

To link to this article: DOI: 10.1080/002075499190338

URL: http://dx.doi.org/10.1080/002075499190338

\section{PLEASE SCROLL DOWN FOR ARTICLE}

\section{Full terms and conditions of use: http://www.informaworld.com/terms-and-conditions-of-access.pdf}

This article maybe used for research, teaching and private study purposes. Any substantial or systematic reproduction, re-distribution, re-selling, loan or sub-licensing, systematic supply or distribution in any form to anyone is expressly forbidden.

The publisher does not give any warranty express or implied or make any representation that the contents will be complete or accurate or up to date. The accuracy of any instructions, formulae and drug doses should be independently verified with primary sources. The publisher shall not be liable for any loss, actions, claims, proceedings, demand or costs or damages whatsoever or howsoever caused arising directly or indirectly in connection with or arising out of the use of this material.

(c) Taylor and Francis 2007 
INT. J. PROD. RES., 1999, vOL. 37, NO. 13, 2895-2914

\title{
Facility layout of irregular-shaped departments using a nested approach
}

\author{
A. R. MCKENDALL JR ${ }^{\dagger}$, J. S. NOBLE $\dagger^{*}$ and C. M. KLEIN $\dagger$
}

The facility layout problem is a very difficult and widely studied optimization problem. As a result, many facility layout models and techniques have been developed. However, the literature does not fully consider or control irregularshaped departments. In this paper, the nested facility layout problem is defined whereby irregular-shaped departments (i.e. L-shaped, O-shaped or U-shaped) can be generated and controlled. This is a unique problem that can be used to efficiently layout workstations, storage areas and other departments within departments, while arranging the departments with respect to an objective. The objective considered here is to minimize material handling cost. We present a formulation and solution technique for the nested facility layout problem. The formulation consists of a modification of Montreuil's mixed-integer problem (MIP) to consider nesting departments. Finally, for illustrative purposes, several example problems are solved using the solution technique presented. The nested facility layout model can be used to either produce a more realistic and detailed block layout, or to group departments together (or nest departments within departments), thus enabling larger facility layout problems to be solved.

\section{Introduction}

The facility layout problem is the problem of arranging departments within a facility with respect to optimizing a stated objective. Mecklenburgh (1985) and Francis et al. (1992) define the following objectives that may be considered in determining the layout.

(1) Minimize material handling cost, time and frequency of handling.

(2) Minimize capital and operating cost in equipment and plant.

(3) Minimize overall production lead time.

(4) Increase effective and economical use of space.

(5) Facilitate the manufacturing process and flow of operation.

(6) Provide for employee convenience, safety and comfort.

(7) Maintain flexibility of arrangement and operation.

(8) Minimize variation in types of material handling equipment.

(9) Facilitate the organizational structure and managerial decision-making.

(10) Minimize hazard and nuisance to the public.

(11) Provide for safe and efficient construction.

(12) Provide for legal considerations, e.g. health, emergency and environmental concerns.

Revision received October 1998.

$\dagger$ Department of Industrial and Manufacturing Systems Engineering, E3437 Engineering Building East, University of Missouri-Columbia, Columbia, MO 65211, USA.

*To whom correspondence should be addressed. 
However, two types of objectives are typically considered: adjacency based and distance based. The adjacency-based (objectives 1-12) and distance-based objectives (objectives 1-5) can act as surrogate objectives. For example, minimization of material handling cost, a distance-based objective, reduces material movement. According to Askin and Standridge (1993, p. 204), 'reduced material movement translates into reductions in required aisle space, lower work-in-process (WIP) levels and throughput times, less product damage and obsolescence, reduced storage space and utility requirements, simplified material control and scheduling, and less overall congestion'. Hence, when minimizing material handling cost, other objectives are achieved simultaneously. Another example is the objective of facilitating the manufacturing process and flow of operation, an adjacency-based objective. This objective can ensure that successive processes are adjacent. Therefore, a single unit can be moved at a time. As a result, WIP and cost for material handling equipment is reduced.

When considering distance-based objectives, a distance measure and the input/ output locations (e.g. centroids or pickup/delivery points) of the departments are required to determine the distance between two departments. The two most commonly used distance measures are rectilinear and Euclidean. In this paper, we are concerned with the objective of minimizing the sum of the product of all the flow values, unit cost and rectilinear distance between department centroids. We assume that the unit cost (i.e. the cost of moving a unit load 1 distance unit between departments) equals one, as the flow values can be defined as the product of the flow between departments and their unit cost.

After determining the objective(s), the representation of the solution to the facility layout problem needs to be addressed. A block layout is one way of representing the solution to the facility layout problem. It specifies the relative location and size of each department within a facility. Furthermore, the block layout can be represented in either a discrete or continuous fashion. A discrete representation of the block layout uses a collection of grids to represent departments. However, a continuous representation uses the centroid, area (or perimeter) and the width (and/or length) of a department to specify the exact location of the department within a facility. Hence, the algorithms used to solve the facility layout models (discussed below) use a discrete or continuous layout representation. In the literature, most of the facility layout algorithms use a discrete representation to generate the block layout.

A number of models have been developed for the discrete representation of the facility layout problem. The facility layout problem was first modelled as a Quadratic Assignment Problem (QAP) by Koopmans and Beckmann (1957), where all the departments were of equal sizes. Furthermore, the facility layout problem has also been formulated as linear integer programming problems and mixed integer programming problems using the discrete representation. A review of the QAP-based formulations, discussed in this section, and algorithms for solving these problems can be found in Kusiak and Heragu (1987). According to Meller and Gau (1996), 'optimal solutions to general cases of the QAP can only be found for problems with less than 18 departments, and it is not possible to solve even small problems with a few unequal-area departments'.

A limited number of models have been developed for the continuous representation of the facility layout problem. Montreuil (1990) presented a unique and theoretically attractive Mixed-Integer Programming (MIP) model for the facility layout problem based on a continuous representation. A similar model was developed 
during the same period by Heragu and Kusiak (1991). Heragu and Kusiak's models are formulated as a linear continuous program with absolute values in the objective function and constraints and a linear mixed integer program. The authors concluded that their formulation is advantageous because the location of sites need not be known a priori, and the areas of the departments are unequal. In contrast to Montreuil's MIP model where the dimensions of the departments are decision variables, Heragu and Kusiak's model contains departments with fixed dimensions.

In this paper, Montreuil's MIP formulation is modified by adding additional constraints to model the nested facility layout problem. Although the MIP formulation has many advantages over QAP-based models, it is more difficult to solve computationally. As a result, optimal solutions to problems with nine or more departments have not been reported in the literature, using the MIP formulation. However, the MIP model does have advantages over QAP-based models. These are:

- the department dimensions vary, and they are of different shapes and sizes;

- continuous representation is not discrete;

- location of departments is not determined a priori;

- the shape of the departments is controlled, and irregular- and strange-shaped departments are not an issue;

- more flexible, as it can incorporate other issues, e.g. material handling system, aisles, pickup/delivery points (as opposed to centroids), multi-objective function, etc.

In the literature, irregular-shaped departments are considered to be departments which may be very long and narrow, may have an odd shape (non-rectangular), or may be split (the worst case). QAP-based models and some graph theoretic models generate irregular-shaped departments in the following manner. Initially, during layout planning, the departments are rectangular in shape. However, after applying a layout algorithm to the facility layout model, the departments can assume rectangular and/or irregular shapes. Algorithms, in the literature, which can result in irregular-shaped departments include: CRAFT by Armour and Buffa (1963); ALDEP by Seehof and Evans (1967); CORELAP by Lee and Moore (1967); SPIRAL by Goetschalckx (1992); and MULTIPLE by Bozer et al. (1994). In order to control department shape, Liggett and Mitchell (1981) and Bozer et al. (1994) present 'shape measures' that are used to detect and penalize irregularshaped departments. One concern is that using these shape measures may result in generating substandard layouts (i.e. the optimal solutions or a number of feasible layouts may be omitted). According to Tompkins et al. (1996, p. 360), 'none of the shape measures can be used to prescribe a particular shape for a department'.

In contrast, the original MIP model is restricted to facility layout problems with rectangular department shapes. However, the model can be modified to consider the shapes of certain departments that must be adjusted to accommodate a non-rectangular building. This modification to define L-shaped, U-shaped and other arbitrary, non-rectangular departments with a continuous representation is not straightforward (Tompkins et al. 1996, p. 329). Consequently, these modifications are lacking in the literature.

In the following section, we define the nested facility layout problem. This problem is equivalent to solving the facility layout problem using a continuous representation where irregular-shaped departments are produced. Additionally, a formulation of the nested facility layout model using a modification of 


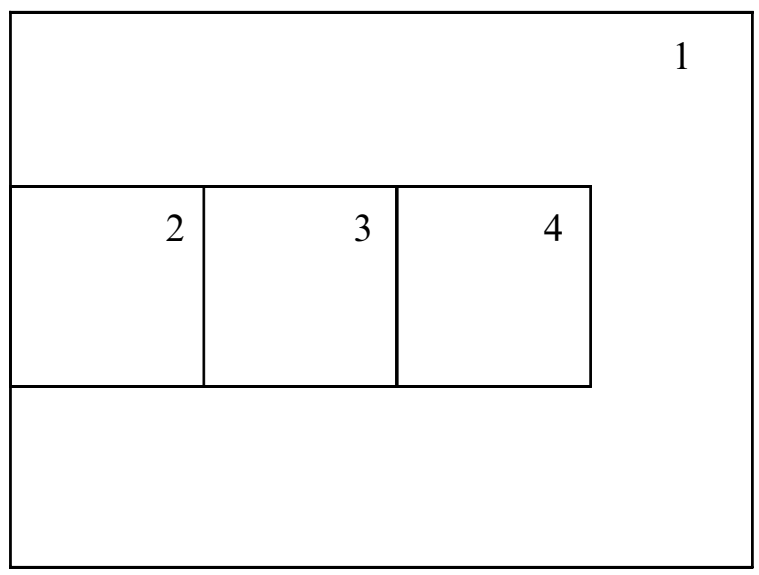

Figure 1. Nestable and Nested Departments.

Montreuil's MIP formulation with an additional set of constraints is presented. Next, a technique is presented and used to solve this problem. Lastly, examples are solved using the techniques presented in this paper.

\section{The nested facility layout model}

\subsection{Definition}

The nested facility layout problem is the arrangement of departments within a facility that minimizes the material handling cost such that one or more departments are placed within another department. The department(s) placed within a department is called the nested department(s). The department containing the nested department(s) is called the nestable department. In this paper, the nested facility layout problem is restricted to at most four nested departments per nestable department. In figure 1, department 1 is a nestable department, and departments 2-4 are the corresponding nested departments. Notice that department 1 is U-shaped.

\subsection{Motivation}

Departments are space in a facility used for providing services, administrative processes, storage and production. A production department can be either a single workstation (i.e. a department that contains a single machine, storage areas for work in process, and a desk) or a collection of workstations. A collection of workstations can have one of a variety of different production layouts (i.e. product, job shop, group technology or hybrid layout). The following presents two cases that justify the use of the nested facility layout problem.

(1) Consider the case where there are several production departments with a single workstation. Furthermore, each department has 'extremely' large flow values with one or more departments and/or there exists a 'strong' relationship(s) between departments. Also, none of the departments conflicts with each other (e.g. paint and welding department). Each production department can then be represented as a nested department, and the nestable department can be a decentralized storage department used to support the production departments. The nested facility layout problem can be used to efficiently arrange the departments according to intradepartmental and 


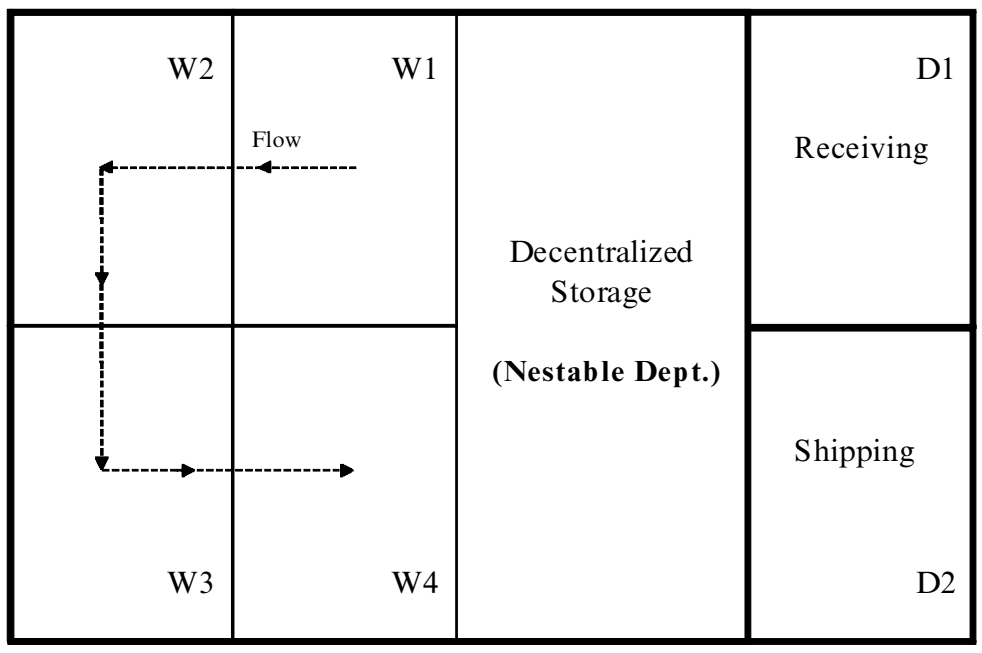

Figure 2. Example of a Detailed Block Layout.

interdepartmental flow. This case can be extended to include other nested and nestable departments. Given that the above conditions hold, the nested departments can be a combination of offices, storage areas, service departments or production departments, and the nestable department can assume any one of the department types. This is illustrated in the examples presented later.

(2) Also, the collection of workstations in a production department can be represented as the nested departments, and the production department containing the nested departments (which can be a decentralized storage department) can be represented as the nestable department. If the flow between the workstations is known, then the type of layout is known. Figure 2 illustrates this example. The collection of workstations (W1-W4, which are the nested departments) is arranged according to the flow between the workstations (intradepartmental flow), and the flow between the nestable department and the outer departments D1 and D2 (interdepartmental flow). Thus, a nested facility layout problem is created which considers the internal structure and/ or internal layout of the departments. Hence, it produces a more detailed block layout. Notice, the same process can be applied to production departments which have a job shop, group technology or a hybrid layout.

In summary, the two cases above illustrate how the nested facility layout problem can be used. It can be used either to group departments together to solve larger facility layout problems (case 1), or to produce a more detailed block layout by considering the internals of a set of departments (case 2). When considering case 2 , the nested and corresponding nestable departments are known (i.e. the workstation(s), storage area(s), etc. within each department). Furthermore, the dimensions of the nested and nestable departments are known. Thus, the techniques used to solve case 1 problems can be used to solve case 2 problems. Hence, the rest of this paper focuses on solving case 1 problems. The assumptions, notation and formulation for this problem are given next. 


\subsection{Assumptions}

The following assumptions are made.

(1) Initially, all departments are rectangular.

(2) The nested and nestable departments are determined and associated.

(3) The initial length and width of all the departments are known, and the nestable departments' dimensions are determined.

(4) The building dimensions are known.

(5) After solving the nested facility layout problem, nestable department centroids can lie outside the department.

In assumption (1), prior to solving the nested facility layout problem, all the departments are rectangular in shape. However, after placing the nested departments within their corresponding nestable department, the nestable department can assume irregular shapes. The nested set of constraints, introduced in the formulation section, can be used to restrict the nested departments to certain locations within their nestable departments.

In assumption (2), nested and nestable departments are determined and associated by using an algorithm developed in this paper. Given the flow between the departments, the maximum number of nested departments per nestable department, and the maximum number of nestable departments, the algorithm determines and associates the nested and nestable departments based on departments with high flow values and a dominance rule. This algorithm is presented in $\S 3.1$. After applying the algorithm, validating the results is necessary to ensure that nested and nestable departments are matched correctly. In other words, ensure that the function, internal structure, and/or internal layout of the nested and corresponding nestable departments do not conflict.

Initially, in assumption (3), the sizes of all the departments are known and can be determined by considering the space needed for equipment, materials and personnel such that the facility operates most efficiently (Tompkins et al. 1996, p. 96). However, the nestable departments are expanded due to the area lost when nesting departments. Note that the more nested departments in a nestable department, the larger the nestable department. In other words, the size of a nestable department is a function of the internal layout of the nested and nestable departments, the number of corresponding nested departments, and the nested departments' shapes and sizes. After arranging the nested departments, the area of the corresponding nestable department is the area minus the nested departments' area. Thus, careful consideration is taken when determining the dimensions of the nestable departments. Furthermore, correctly determining the shapes and sizes of the nestable departments (including expansion and re-layout considerations) prevents splitting and inefficient use of the departments.

As mentioned previously, after solving the nested facility layout problem, the nestable departments can assume irregular shapes. Therefore, in assumption (5), the centroid of the nestable departments can lie outside the departments. This assumption is often used in the literature, although it underestimates the objective function value. One means of relaxing this assumption is to use pickup and delivery points as opposed to centroids, although this will be left as the subject of future work. The notation and formulation presented next is based on the formulation of Montreuil's MIP (Montreuil 1990) given in Meller and Gau (1996). 


\subsection{Notation}

The indices used are as follows:

$i, j \in D=$ the set of all departments where $D=1, \ldots, N(N=$ number of departments);

$d, e \in N D^{\prime}=$ the set of all departments except the nested departments where $N D^{\prime} \subset D$;

$q, r \in N D=$ the set of nested departments where $N D \subset D$;

$s \in N S=$ the set of nestable departments where $N S \subset D \quad(|N S| \leq|N D|<$ $|D|=N)$;

$(R, s)=$ the nestable department $s$ and its corresponding set of nested departments $R$.

The parameters are as follows:

$F=f_{i j}=$ the positive flow between departments $i$ and $j$, where $|F|=M$, and $f_{m}=$ the $m$-th positive flow from department $i(m)$ to department $j(m)$;

$L_{i}=$ half the length of department $i$ (x-direction);

$W_{i}=$ half the width of department $i$ (y-direction);

tot $L=$ length of the building in the $x$-direction;

tot $W=$ width of the building in the $y$-direction.

The variables are as follows:

$\left(x_{i}, y_{i}\right)=$ centroid of department $i$

$d x_{m}^{+}, d x_{m}=$ flow distance from the centroid of department $i(m)$ to the centroid of department $j(m)$ in the $x$-direction;

$d y_{m}^{+}, d y_{m}^{-}=$flow distance from the centroid of department $i(m)$ to the centroid of department $j(m)$ in the $y$-direction;

$$
\begin{aligned}
& z_{i j}^{x}= \begin{cases}0, & \text { if } i \text { is west (left) of } j \\
1, & \text { otherwise }\end{cases} \\
& z_{i j}^{y}= \begin{cases}0, & \text { if } i \text { is north (above) of } j \\
1, & \text { otherwise }\end{cases}
\end{aligned}
$$

These variables are called the relative location decision variables. Now, we present the formulation.

\subsection{Formulation}

$$
\operatorname{Min} \Sigma_{m} f_{m}\left(d x_{m}^{+}+d x_{m}^{-}+d y_{m}^{+}+d y_{m}^{-}\right)
$$

Subject to

$$
\begin{array}{lr}
d x_{m}^{+} \geq x_{i(m)}-x_{j(m)} & \forall m \\
d x_{m}^{-} \geq x_{j(m)}-x_{i(m)} & \forall m \\
d y_{m}^{+} \geq y_{i(m)}-y_{j(m)} & \forall m \\
d y_{m}^{-} \geq y_{j(m)}-y_{i(m)} & \forall m
\end{array}
$$




$$
\begin{array}{cc}
L_{d} \leq x_{d} \leq \operatorname{tot} L-L_{d} & \forall d \\
W_{d} \leq y_{d} \leq \operatorname{tot} W-W_{d} & \forall d \\
x_{d}-x_{e}+L_{d}+L_{e}-\operatorname{tot} L^{*} z_{d e}^{x} \leq 0 & \forall d, e(d>e) \\
x_{e}-x_{d}+L_{e}+L_{d}-\operatorname{tot} L^{*} z_{e d}^{x} \leq 0 & \forall d, e(d>e) \\
y_{d}-y_{e}+W_{d}+W_{e}-\operatorname{tot} W^{*} z_{d e}^{y} \leq 0 & \forall d, e(d>e) \\
y_{e}-y_{d}+W_{e}+W_{d}-\operatorname{tot} W^{*} z_{e d}^{y} \leq 0 & \forall d, e(d>e) \\
2 \leq z_{d e}^{x}+z_{e d}^{x}+z_{d e}^{y}+z_{e d}^{y} \leq 3 & \forall d, e(d>e) \\
x_{r}+L_{r} \leq x_{s}+L_{s} & \forall(r, s) \\
x_{r}-L_{r} \geq x_{s}-L_{s} & \forall(r, s) \\
y_{r}+W_{r} \leq y_{s}+W_{s} & \forall(r, s) \\
y_{r}-W_{r} \geq y_{s}-W_{s} & \forall(r, s) \\
x_{q}-x_{r}+L_{q}+L_{r}-\operatorname{tot} L^{*} z_{q r}^{x} \leq 0 & \forall q, r \in R(q>r), \forall s \\
x_{r}-x_{q}+L_{r}+L_{q}-\operatorname{tot} L^{*} z_{r q}^{x} \leq 0 & \forall q, r \in R(q>r), \forall s \\
y_{q}-y_{r}+W_{q}+W_{r}-\operatorname{tot} W^{*} z_{q r}^{y} \leq 0 & \forall q, r \in R(q>r), \forall s \\
y_{r}-y_{q}+W_{r}+W_{q}-\operatorname{tot} W_{z}^{*} z_{r q}^{y} \leq 0 & \forall q, r \in R(q>r), \forall s \\
2 \leq z_{q r}^{x}+z_{r q}^{x}+z_{q r}^{y}+z_{r q}^{y} \leq 3 & \forall q, r \in R(q>r), \forall s \\
x_{i}, y_{i}, d x_{m}^{+}, d x_{m}^{-}, d y_{m}^{+}, d y_{m}^{-} \geq 0 \text { and } z_{d e}^{x}, z_{d e}^{y}, z_{q r}^{x}, z_{q r}^{y}=0 \text { or } 1 .
\end{array}
$$

The objective function (1) is based on flow $\times$ rectilinear distance between department centroids. Since the rectilinear distance function contains absolute values, the standard linear programming transformation to linearize them is used in equations (2)(5). In equations (6) and (7), each department, except the nested departments, is constrained to be within the facility. In equations (8)-(11), the relative location decision variables are utilized to ensure that departments, except the nested departments, do not overlap. The constraint set (12) ensures that relative department location constraints are relaxed in two or three directions. In other words, when the location of department $d$ is either east or west, and either north or south of department $e$, constraint set (12) is said to be relaxed in two directions. However, constraint set (12) is said to be relaxed in three directions when the location of department $d$ is one of the following. (i) neither east nor west but either north or south of department $e$; or (ii) neither north nor south but either east or west of department $e$. In equations (13)-(16), the nested constraint sets, each nested department is constrained to be within its corresponding nestable department (figure 3). In equations (17) $-(20)$, the relative location decision variables are utilized to ensure that the nested departments do not overlap. Constraint set (21) ensures that relative department location constraints are relaxed in two or three directions. Constraint sets (2)-(12) are in Montreuil's MIP formulation minus the constraint sets that constrain the minimum and maximum lengths of the department rectangles and the perimeter of the facility. These constraint sets are omitted because, as previously 


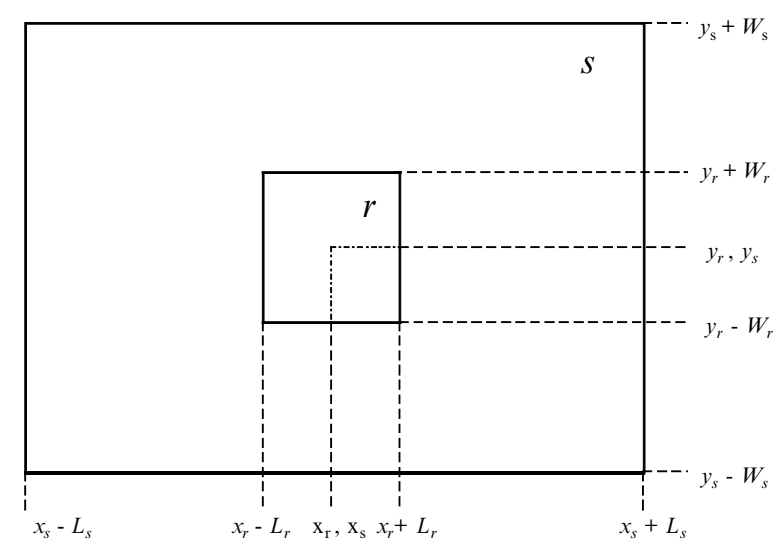

Figure 3. Nested Department $r$ within Nestable Department $s$.

mentioned, the dimensions of the building and the departments are known and determined a priori.

Note in figure 3, in order to fix department $r$ (the nested department) to the upper-right corner of department $s$ (the nestable department), the inequalities in constraints (13) and (15) must be changed to equalities. Likewise, the set of nested departments can be constrained to the boundary of their corresponding nestable department. Hence, the nested departments can be fixed to a particular location within its nestable department, and the shape of the nestable department can be controlled. The solution technique for the nested facility layout problem is presented next.

\section{Solution procedure}

A divide and conquer approach is used to solve the nested facility layout model (i.e. a series of subproblems is solved to yield the solution to the problem). The following steps are used to solve the nested facility layout problem.

\subsection{Algorithm}

Step 0. (a). Determine and associate the nested and nestable departments.

(i) Specify the maximum number of nested departments per nestable departments and the maximum number of nestable departments.

(ii) Rank the total flow values between departments in descending order.

(iii) Select the highest flow values (top 25\%). From this selection, group the flow between the same departments together. This gives potential nestable departments.

(iv) Use a dominance rule to determine the nestable departments and its nested department(s). The groups with the highest flow value(s) dominate.

(v) Validate the results to ensure that there is no conflict between departments.

(b) Determine the sizes of the nestable departments (e.g. length of nestable department equals sum of the lengths of its nested departments and the 
initial length of the nestable department; likewise, for the width of the nestable department).

Step 1. Solve the MIP model:

Minimize Objective Function (1)

Subject to Constraints (2)-(16).

Step 2. Solve the MIP model:

Minimize Objective Function (1)

Subject to Constraints (2)-(21)

where the relative location variables of all the departments, except the nested departments, are fixed and set to the values obtained in Step 1 (i.e. set the $z_{d e}$ variables to the values obtained in Step 1).

Step 3. Solve the MIP model:

Minimize Objective Function (1)

Subject to Constraints (2)-(21)

where the relative location variables of all the nested departments are fixed and set to the values obtained in Step 2 (i.e. set the $z_{q r}$ variables to the values obtained in Step 2).

Step 4. Repeat steps 2 and 3 above until the objective function value shows no further improvement. In other words, after step 3, solve the MIP model in step 2 where the $z_{d e}$ variables are fixed and set to the values obtained in step 3. Continue to alternate between setting the $z_{q r}$ and $z_{d e}$ variables. Continue until the objective function value shows no improvement.

Step 1 arranges all the departments, and it allows the nested departments, in the same nestable department, to overlap. It is obvious that by allowing the nested departments to overlap, it is possible that the centroids of the nested departments can stack on top of each other. Step 2 is then used to separate the overlapping nested departments. In this step, we fix the relative location of all the departments, except the nested departments, and efficiently arrange the nested departments. In step 3, the relative locations of the nested departments are fixed, and the other departments are allowed to shift. This is used to improve the material handling cost. In step 4, the process is continued between fixing the relative location of all the departments, except the nested departments, and the relative location of the nested departments until the objective function shows no improvement. Hence, the solution obtained is a solution to the nested facility layout problem. In section 4.1, the details of the algorithm are explained by solving an 8-department problem.

The nested facility layout problem can be solved directly by using a branch and bound algorithm for the MIP (CPLEX). This approach yields the optimal solution for a particular partition of nested and nestable departments, but it requires much more computer time for 'large' problems. In the procedure discussed in this paper, several of the binary variables are set, which enables us to solve larger problems using less computer time. This will be illustrated in the next section by solving several example problems. Often in the literature, Montreuil's MIP model is solved by setting the binary variables then solving the resulting linear program. The binary variables are determined using a heuristic procedure. Banerjee et al. (1992), Montreuil et al. (1993), Lacksonen (1994), and Banerjee and Zhou (1995) illustrate this approach.

The algorithm yields good quality solutions in reasonable computation time. For example, in section 4, 8-, 12- and 15-department problems were solved in $29.13 \mathrm{~s}$ (in 
four iterations), $97.15 \mathrm{~s}$ (in four iterations) and $2.79 \mathrm{~h}$ (in five iterations), respectively. Even though the solution obtained from the algorithm was the same when solving the MIP directly for the 8-department problem, this solution is optimal only for this partition of nested and nestable departments. However, a sensitivity analysis on pairs of nested and nestable departments was performed for the 8- and 12-department problems, and will be given in section 4. It was shown, for the 8-department problem, that the algorithm (step 0 ) selected the best partition of nested and nestable departments. However, for the 12-department problem, the algorithm (step 0) selected the second best partition of nested and nestable departments. Furthermore, for the 12- and 15-department problems, the solutions obtained from the algorithm were less than $1 \%$ from the optimal solutions (for the given partitions of nested and nestable departments). The algorithm produces suboptimal solutions because at each step the best solution is selected. Therefore, the algorithm is a steepest-descent heuristic, and the solution may get 'stuck' at a local optimum. Although the algorithm does not guarantee optimal solutions, good solutions are provided. Furthermore, the algorithm can provide good layouts for up to approximately 32 departments. In the next section, the 8-, 12- and 15-department example problems are solved using the techniques discussed in this paper.

\section{Illustrative examples}

In this section, 8-, 12- and 15-department nested facility layout problems are solved. The flow data were taken from Nugent et al. (1968). MPL (Mathematical Programming Language) software was used to generate the MIP models. Then CPLEX was used to solve these models. The problems were solved on a P5-100 personal computer.

\subsection{8-Department problem}

First, the nestable and nested departments are determined and associated. Using the algorithm (step 0), the maximum number of nested departments per nestable department and the maximum number of nestable departments are specified as two. In Nugent et al. (1968), for the 8-department problem, the highest total flow values (the top 25\%) are 11 (between departments 5 and 6, 8 and 4, and 8 and 7), 10 (between departments 1 and 8), 9 (between departments 4 and 5), and 7 (between departments 1 and 4, and 3 and 8). Since departments (groups) 4, 5 and 8 have the highest flow values and more than one flow value in the top $25 \%$, they are potential nestable departments. Note, department 4 is dominated by department 8 because they both share the highest flow value, and department 8 has larger flow values (department 8 has 11, 11, 10 and 7, and department 4 has 11, 9 and 7). Therefore, the nestable departments are departments 5 and 8 . Next, the nested departments with the highest flows with the nestable departments are assigned to those nestable departments until the maximum number of nested departments per nestable departments has been reached. After grouping the departments and using the dominance rule, department 6 is nested (or placed) in 5 and departments 4 and 7 are nested in 8 . It is important to verify that no conflicts occur between nested and nestable departments.

The dimensions of a nestable department are determined by considering the space required for the department, the number of nested departments, the shapes and sizes of the nested departments, and the function and internal layout of the nested and nestable departments. It is known that each department requires 


\begin{tabular}{ccc}
\hline Department & Length $(\mathrm{ft})$ & Width $(\mathrm{ft})$ \\
\hline $1-4,6$ and 7 & 50 & 50 \\
5 & 100 & 100 \\
8 & 150 & 150 \\
Building & 250 & 200 \\
\hline
\end{tabular}

Table 1. Department and building dimensions for the 8-department problem.

\begin{tabular}{clc}
\hline Step & Solution & Computer time (s) \\
\hline 1 & 5250 (infeasible) & 14.46 \\
2 & 5500 (feasible) & 0.28 \\
3 & 5400 (feasible) & 14.11 \\
4 & 5400 (feasible) & 0.28 \\
Final solution & 5400 (feasible) & 29.13 \\
Solve MIP directly & 5400 (feasible) & 33.84 \\
\hline
\end{tabular}

Table 2. Solution summary for the 8-department problem.

$50 \times 50 \mathrm{ft}(15.24 \times 15.24 \mathrm{~m})$ of space. However, due to nesting, the nestable departments, departments 5 and 8 , require $100 \times 100 \mathrm{ft}(30.48 \times 30.48 \mathrm{~m})$ and $150 \times 150 \mathrm{ft}$ $(45.72 \times 45.72 \mathrm{~m})$ of space, respectively. Furthermore, careful consideration is needed when determining the shapes and sizes of the nestable departments to prevent splitting and inefficient use of the departments. Table 1 gives the dimensions of the departments and the building in feet (departments do not have to be square shaped). Next, the formulation and technique, presented in this paper, are used to solve this problem.

Initially, the original facility layout problem with eight departments of equal size $(50 \times 50 \mathrm{ft}$ or $15.24 \times 15.24 \mathrm{~m})$ using Montreuil's MIP formulation [constraints (1)(12)] was solved without nesting. The optimal solution of 5350 was obtained in $34.55 \mathrm{~h}$. The nested facility layout model yields a solution of 5400 in $29.13 \mathrm{~s}$. Since the department sizes are unequal in the nested problem, the solution values should not be compared. The purpose of solving Montreuil's MIP model was to compare the time required to solve the facility and nested layout models. The details of the nested problem are given in table 2. Step 1 yields a solution of 5250 in $14.46 \mathrm{~s}$, as shown in figure 4 . Note that the solution is infeasible and underestimated, due to the overlapping nested departments 4 and 7. Step 2 yields a solution of 5500 in $0.28 \mathrm{~s}$ (figure 5). This problem is solved more quickly, because the problem size is decreased since the relative locations of all the departments except the nested departments are fixed and only the arrangement of the nested departments is considered. Step 3 yields a solution of 5400 in $14.11 \mathrm{~s}$. In this step, the relative locations of the nested departments 4 and 7 are fixed, and the other departments were arranged such that the material handling cost is minimized. In step 4, the objective function value (solution obtained in $0.28 \mathrm{~s}$ ) showed no improvement. Hence, the solution in step 4 (figure 6) is the solution to the nested facility layout problem where departments 5 and 8 are $\mathrm{O}$ shaped and U-shaped, respectively. Next, the nested facility layout model was solved directly where the binary variables were not set. The optimal solution (5400) for this partition of nested and nestable departments was obtained in $33.84 \mathrm{~s}$, as shown in 


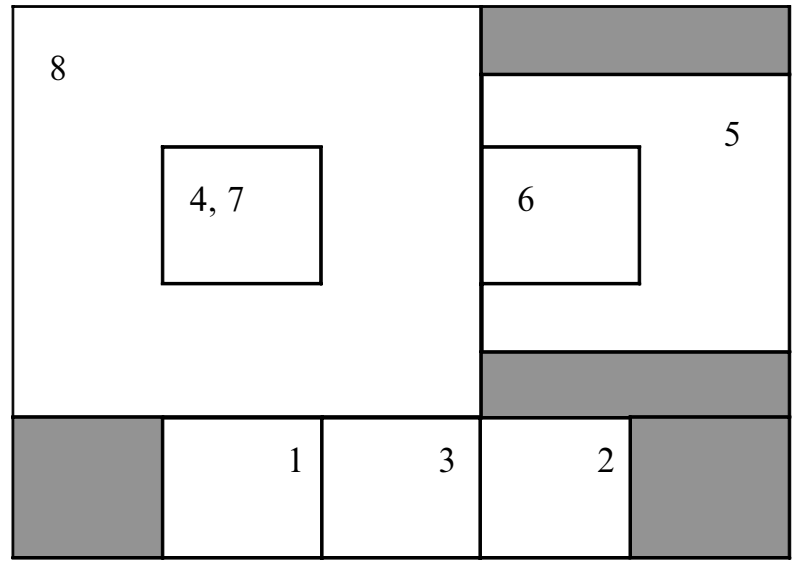

Figure 4. Step 1 Solution for the 8-Department Problem.

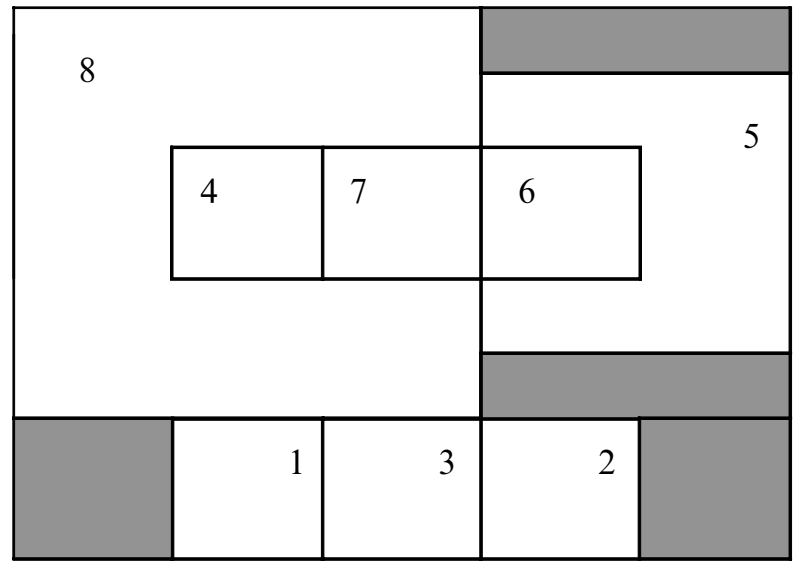

Figure 5. Step 2 Solution for the 8-Department Problem.

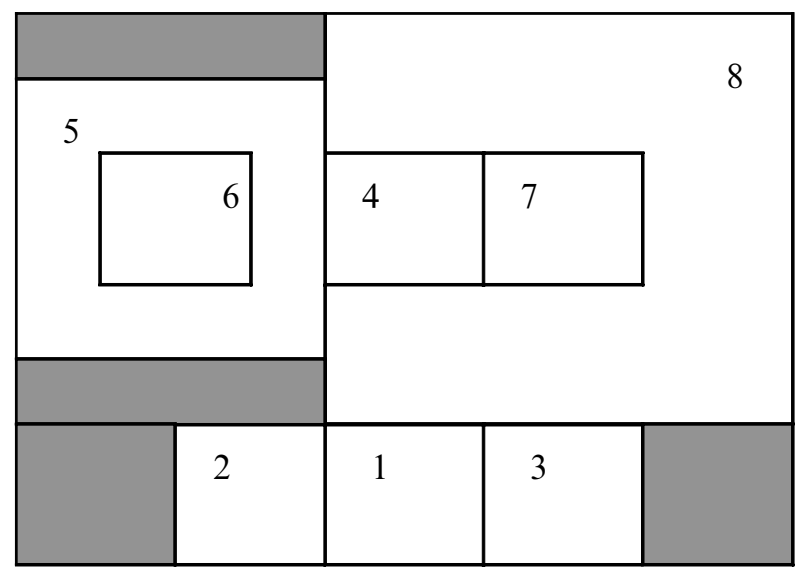

Figure 6. Steps $3 \& 4$ Solution for the 8-Department Problem. 


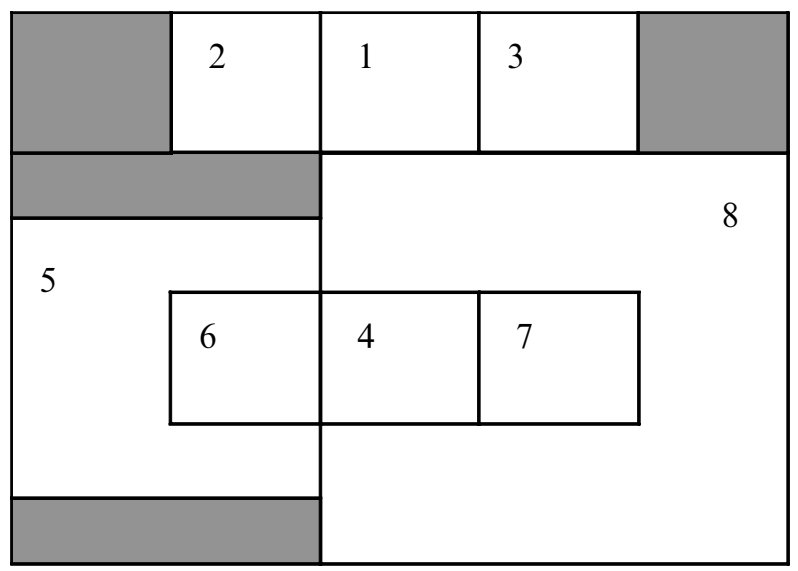

Figure 7. Solution Obtained from Solving the 8-Department MIP Directly.

figure 7. Note that the layout of the departments is slightly different (i.e. department 5 is U-shaped). Thus, this validates that the solution obtained in step 4 is the optimal solution (for this partition of nested and nestable departments) to the 8-department nested facility layout problem.

In the above problem, the partition obtained by the algorithm which nested department 6 in 5 and departments 4 and 7 in 8 yielded a solution of 5400 . However, a sensitivity analysis was performed to determine if a partition exists which yields a better solution than 5400 when the maximum number of nested departments per nestable department and the maximum number of nestable departments are both two. This was achieved by partitioning the departments with the highest flow values (top $25 \%$, table 3 ). When nesting only one department per nestable department (problems 1-10), the nestable department dimension is $100 \times 100 \mathrm{ft}(30.48 \times 30.48 \mathrm{~m})$. Problems 5 and 6 yield the best solution $(5500)$ by nesting department 4 in 8 , and either 6 in 5 or 5 in 6 , respectively. When nesting two departments (problems 11-31), the nestable department dimensions are $150 \times 150 \mathrm{ft}(45.72 \times 45.72 \mathrm{~m})$. Problem 11 yields an infeasible solution (i.e. department 4 is split). Problems 30 and 31 yield the best solution (5400) by nesting 4 and 7 in 8 , and either 6 in 5 or 5 in 6 , respectively. Thus, nesting more departments with high flow between the nested and nestable departments may give better solutions. Therefore, more analysis is needed to determine the number of nested departments per nestable department and the number of nestable departments.

\subsection{2-Department problem}

First, the nestable and nested departments are determined and associated, as in the previous example. For the 12-department problem, departments 1, 4 and 7 are nested in 8 , and departments 2, 3, 11 and 12 are nested in 9. Next, the dimensions of the nestable departments are determined. Table 4 gives the dimensions of the departments and the building in feet. Montreuil's MIP formulation cannot solve the 12department problem optimally in reasonable computational time. However, the 12department nested problem was solved by following the same procedure as in the 8-department problem (table 5). Steps 1 and 2 yield objective function values of 12350 (in 48.82 s) and 14550 (in 20.97s), respectively. Steps 3 and 4 yield solutions of 14200 in $15.18 \mathrm{~s}$ and $12.18 \mathrm{~s}$, respectively. Thus, the final solution to the 12- 


\begin{tabular}{|c|c|c|c|}
\hline Problem & Partition 1 & Partition 2 & Solution \\
\hline 1 & $1 \rightarrow 8$ & $4 \rightarrow 5$ & 6100 \\
\hline 2 & $1 \rightarrow 8$ & $5 \rightarrow 4$ & 6150 \\
\hline 3 & $1 \rightarrow 8$ & $5 \rightarrow 6$ & 5725 \\
\hline 4 & $1 \rightarrow 8$ & $6 \rightarrow 5$ & 5725 \\
\hline 5 & $4 \rightarrow 8$ & $5 \rightarrow 6$ & 5500 \\
\hline 6 & $4 \rightarrow 8$ & $6 \rightarrow 5$ & 5500 \\
\hline 7 & $7 \rightarrow 8$ & $5 \rightarrow 6$ & 5525 \\
\hline 8 & $7 \rightarrow 8$ & $6 \rightarrow 5$ & 5525 \\
\hline 9 & $7 \rightarrow 8$ & $4 \rightarrow 5$ & 6075 \\
\hline 10 & $7 \rightarrow 8$ & $5 \rightarrow 4$ & 6150 \\
\hline 11 & $5,8 \rightarrow 4$ & $\varnothing$ & $5850 *$ \\
\hline 12 & $4,7 \rightarrow 8$ & $\widetilde{\varnothing}$ & 5550 \\
\hline 13 & $1,3 \rightarrow 8$ & $4,6 \rightarrow 5$ & 6700 \\
\hline 14 & $1,3 \rightarrow 8$ & $4,5 \rightarrow 6$ & 6700 \\
\hline 15 & $1,3 \rightarrow 8$ & $5,6 \rightarrow 4$ & 7250 \\
\hline 16 & $1,4 \rightarrow 8$ & $5 \rightarrow 6$ & 5900 \\
\hline 17 & $1,4 \rightarrow 8$ & $6 \rightarrow 5$ & 5900 \\
\hline 18 & $1,7 \rightarrow 8$ & $4,6 \rightarrow 5$ & 5600 \\
\hline 19 & $1,7 \rightarrow 8$ & $4,5 \rightarrow 6$ & 5600 \\
\hline 20 & $1,7 \rightarrow 8$ & $5,6 \rightarrow 4$ & 6250 \\
\hline 21 & $1,7 \rightarrow 8$ & $5 \rightarrow 4$ & 6325 \\
\hline 22 & $1,8 \rightarrow 4$ & $6 \rightarrow 5$ & 5900 \\
\hline 23 & $1,8 \rightarrow 4$ & $5 \rightarrow 6$ & 5900 \\
\hline 24 & $3,4 \rightarrow 8$ & $5 \rightarrow 6$ & 6050 \\
\hline 25 & $3,4 \rightarrow 8$ & $6 \rightarrow 5$ & 6050 \\
\hline 26 & $3,7 \rightarrow 8$ & $1,5 \rightarrow 4$ & 7100 \\
\hline 27 & $3,7 \rightarrow 8$ & $4,6 \rightarrow 5$ & 6100 \\
\hline 28 & $3,7 \rightarrow 8$ & $4,5 \rightarrow 6$ & 6100 \\
\hline 29 & $3,7 \rightarrow 8$ & $5,6 \rightarrow 4$ & 6750 \\
\hline 30 & $4,7 \rightarrow 8$ & $6 \rightarrow 5$ & 5400 \\
\hline 31 & $4,7 \rightarrow 8$ & $5 \rightarrow 6$ & 5400 \\
\hline
\end{tabular}

Table 3. Partitions of nested and nestable departments for 8department problem.

\begin{tabular}{ccc}
\hline Department & Length $(\mathrm{ft})$ & Width $(\mathrm{ft})$ \\
\hline $1-7,10-12$ & 50 & 50 \\
8 and 9 & 150 & 150 \\
Building & 300 & 250 \\
\hline
\end{tabular}

Table 4. Department and building dimensions for the 12-department problem.

\begin{tabular}{clc}
\hline Step & Solution & Computer time (s) \\
\hline 1 & 12350 (infeasible) & 48.82 \\
2 & 14550 (feasible) & 20.97 \\
3 & 14200 (feasible) & 15.18 \\
4 & 14200 (feasible) & 12.18 \\
Final solution & 14200 (feasible) & 97.15 \\
Solve MIP directly & 14100 (feasible) & $3.74(\mathrm{~h})$ \\
\hline
\end{tabular}

Table 5. Solution summary for the 12-department problem. 


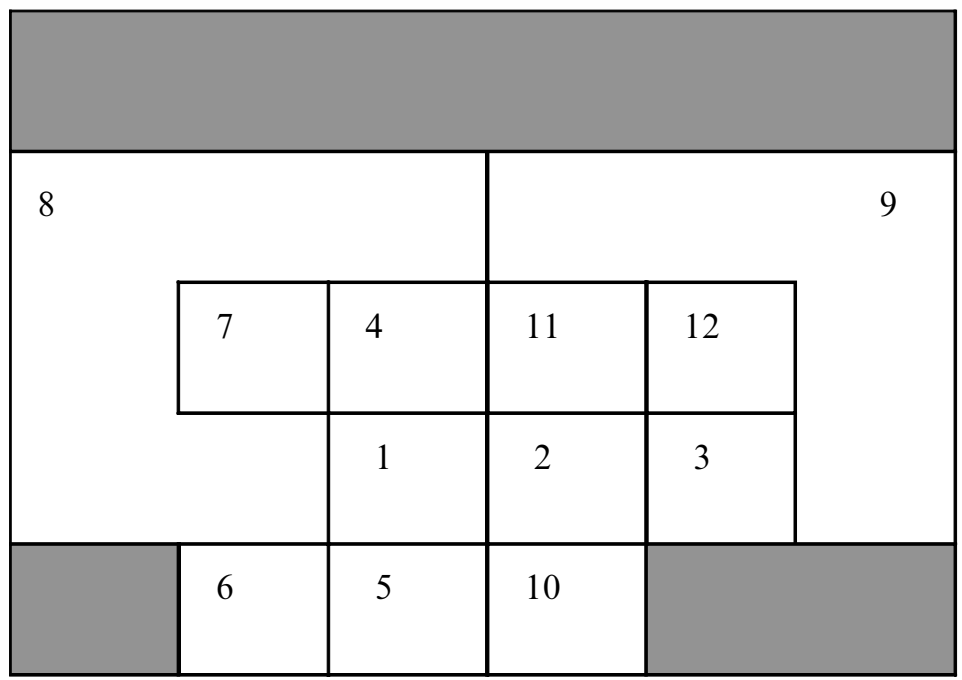

Figure 8. Steps $3 \& 4$ Solution for the 12-Department Problem.

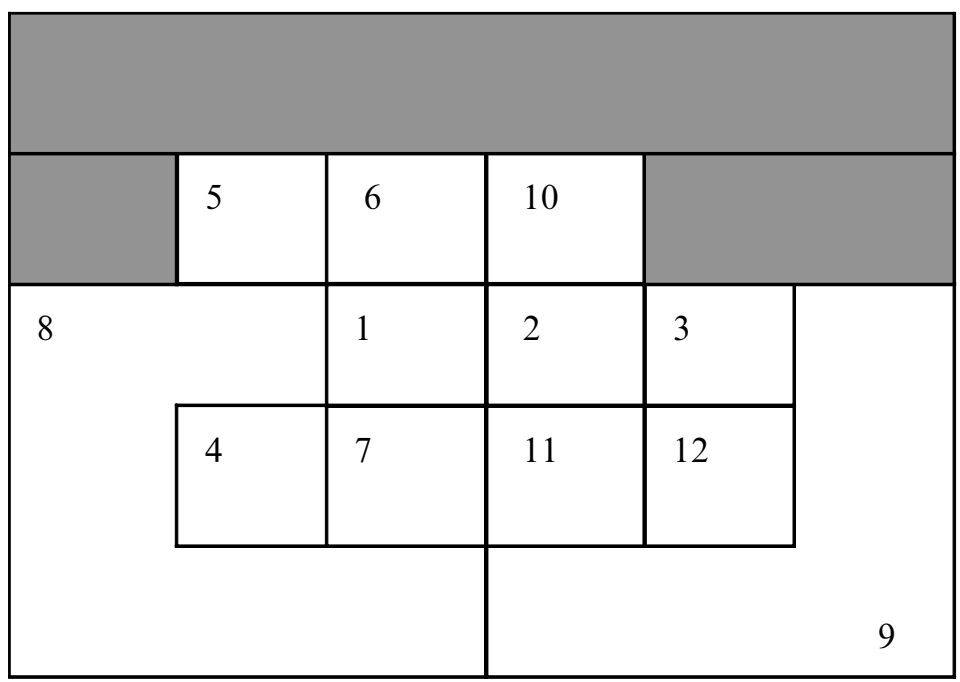

Figure 9. Solution Obtained from Solving the 12-Department MIP Directly.

department nested facility layout problem was obtained in $97.15 \mathrm{~s}$ (figure 8). Next, the nested facility layout model was solved directly (figure 9), and the optimal solution (for this partition of nested and nestable departments) of 14100 was obtained in $3.74 \mathrm{~h}$ (the solution was obtained in $2.54 \mathrm{~h}$, and the remaining $1.20 \mathrm{~h}$ was used to verify optimality). Note that the solution obtained from the algorithm is less than $1 \%$ from the solution obtained from solving the MIP directly. The reason for obtaining a suboptimal solution is due to the nature of the algorithm. Since the algorithm selects the best solution at each step, the algorithm is a steepest-descent algorithm. Therefore, a solution may get 'stuck' at a local optimum. Also, note that in figures 8 and 9 , nestable departments 8 and 9 are U-shaped and L-shaped, respectively. 


\begin{tabular}{cccc}
\hline Problem & Partition 1 & Partition 2 & Solution \\
\hline 1 & $4,7,11,12 \rightarrow 8$ & $2,5,6 \rightarrow 10$ & 14500 \\
2 & $3,7,11,12 \rightarrow 9$ & $1,4 \rightarrow 8$ & 15150 \\
3 & $1,4,7 \rightarrow 8$ & $3,11,12 \rightarrow 9$ & 14750 \\
4 & $1,4,5,7 \rightarrow 8$ & $3,11,12 \rightarrow 9$ & 14550 \\
5 & $5,8,11 \rightarrow 4$ & $3,7,12 \rightarrow 9$ & 15550 \\
6 & $1,4,7 \rightarrow 8$ & $2,3,11,12 \rightarrow 9$ & 14100 \\
7 & $1,5,8 \rightarrow 4$ & $3,7,11,12 \rightarrow 9$ & 14800 \\
8 & $1,5,8 \rightarrow 4$ & $2,3,11,12 \rightarrow 9$ & 15350 \\
9 & $4,6,10 \rightarrow 5$ & $3,7,11,12 \rightarrow 9$ & 14450 \\
10 & $4,6,10 \rightarrow 5$ & $2,3,11,12 \rightarrow 9$ & 14550 \\
11 & $1,3,4,7 \rightarrow 8$ & $2,11,12 \rightarrow 9$ & 14150 \\
12 & $1,4,7,11 \rightarrow 8$ & $2,3,12 \rightarrow 9$ & 14150 \\
13 & $5,11,12 \rightarrow 4$ & $1,3,7 \rightarrow 8$ & 16850 \\
14 & $5,12 \rightarrow 4$ & $1,7,11 \rightarrow 8$ & 16850 \\
15 & $6,10 \rightarrow 5$ & $1,3,4,7 \rightarrow 8$ & 15000 \\
16 & $6,10 \rightarrow 5$ & $1,4,7,11 \rightarrow 8$ & 13900 \\
17 & $1,5,8,11 \rightarrow 4$ & $2,3,7,12 \rightarrow 9$ & 14150 \\
18 & $5,8,11,12 \rightarrow 4$ & $2,3,7 \rightarrow 9$ & 16300 \\
19 & $1,5,11 \rightarrow 4$ & $3,7 \rightarrow 8$ & 17650 \\
20 & $5,11,12 \rightarrow 4$ & $1,3,7 \rightarrow 8$ & 16850 \\
\hline
\end{tabular}

Table 6. Partitions of nested and nestable departments for the 12department problem.

As in the 8-department problem, a sensitivity analysis was performed. The nestable departments' dimensions were $150 \times 150 \mathrm{ft}(45.72 \times 45.72 \mathrm{~m})$. The best solution, obtained in this analysis, is 13900 , where departments 6 and 10 were nested in 5, and departments 1, 4, 7 and 11 were nested in 8 (problem 16, table 6). However, the partitions of nested and nestable departments obtained from the algorithm (problem 6) yielded the second best solution. Thus, the method used to determine and associate nested and nestable departments yields good solutions.

\subsection{5-Department problem}

A 15-department problem was also solved, and it required $2.79 \mathrm{~h}$ to arrive at the solution of 30000 in 5 steps (see tables 7 and 8 , and figures 10 and 11 for department and building dimensions, solution results and block layouts, respectively). Note that nestable department 13 is U-shaped. On the other hand, the nestable departments 3, 6 and 11 are I-shaped. When the nested facility layout model was solved directly, the optimal solution (for this partition of nested and nestable departments) of 29850 was obtained in $27.20 \mathrm{~h}$ (the solution was obtained in $16.67 \mathrm{~h}$, and the remaining $10.53 \mathrm{~h}$ was used to verify optimality). As with the 12-department problem, the algorithm

\begin{tabular}{ccc}
\hline Department & Length (ft) & Width (ft) \\
\hline $1,2,4,5,7-10,12,14$ and 15 & 50 & 50 \\
3, 6 and 11 & 100 & 100 \\
13 & 150 & 150 \\
Building & 350 & 250 \\
\hline
\end{tabular}

Table 7. Department and building dimensions for the 15department problem. 


\begin{tabular}{|c|c|c|c|c|}
\hline \multicolumn{2}{|l|}{3} & 12 & 9 & \multirow[t]{2}{*}{11} \\
\hline 10 & 4 & 7 & 8 & \\
\hline 15 & 5 & 14 & 1 & \multirow[b]{3}{*}{13} \\
\hline \multirow[t]{2}{*}{6} & & & 2 & \\
\hline & & & & \\
\hline
\end{tabular}

Figure 10. Steps $4 \& 5$ Solution for the 15-Department Problem.

\begin{tabular}{|l|l|l|l|l|}
\hline & \multicolumn{2}{|l|}{11} & \multicolumn{2}{|}{13} \\
\hline 12 & 9 & 8 & 2 & 1 \\
\hline 6 & 5 & 7 & 14 & \\
\cline { 2 - 5 } & 15 & 10 & 4 & \\
\hline & & \multicolumn{2}{|c|}{3} & \\
\hline
\end{tabular}

Figure 11. Solution Obtained from Solving the 15-Department MIP Directly.

\begin{tabular}{clc}
\hline Step & Solution & Computer time (s) \\
\hline 1 & 26600 (infeasible) & 1243.01 \\
2 & 30150 (feasible) & 11.29 \\
3 & 30050 (feasible) & 7864.23 \\
4 & 30000 (feasible) & 10.22 \\
5 & 30000 (feasible) & 930.12 \\
Final solution & 30000 (feasible) & $2.79(\mathrm{~h})$ \\
Solve MIP directly & 29850 (feasible) & $27.20(\mathrm{~h})$ \\
\hline
\end{tabular}

Table 8 . Solution summary for the 15-department problem.

produced a suboptimal solution for this partition of nested and nestable departments. However, this solution was less than $1 \%$ from the optimal. Hence, based on the examples given, the proposed solution technique offers a fast and reliable method for solving the nested problem as opposed to solving the problem by standard techniques. 


\section{Conclusions}

In this paper, we present a unique problem which can be used to produce a more detailed block layout by considering the internals of a set of departments. The nested facility layout model can be used to arrange workstations, storage areas and offices within production departments while arranging the departments. Thus, a more detailed block layout is generated. However, the nested facility layout problem can also be used to group departments together, which enables larger facility layout problems to be solved more quickly. This was illustrated by solving 8-, 12and 15-department problems. Furthermore, the techniques used in this paper enable the layout planner to generate and/or use irregular-shaped departments with control. The examples in the previous section generated L-shaped, O-shaped and U-shaped departments. However, the drawbacks and/or areas for further consideration are as follows.

(1) There are limitations to the size of problem that can be solved (in reasonable time).

(2) The solution quality depends on the partition of nested and nestable departments.

(3) The algorithm may get 'stuck' at a local optimum.

(4) The material handling cost is underestimated since the centroids of the irregular-shaped departments can lie outside the departments; as a result, pickup and delivery points should be considered.

\section{References}

Armour, G. C. and Buffa, E. S., 1963, A heuristic algorithm and simulation approach to relative location of facilities. Management Science, 9, 294-309.

Askin, R. G. and Standridge, C. R., 1993, Modeling and Analysis of Manufacturing Systems (New York: Wiley), pp. 204-253.

Banerjee, P., Montreuil, B., Moodie, C. L and Kashyap, R. L, 1992, A modelling of interactive facilities layout designer reasoning using qualitative patterns. International Journal of Production Research, 30, 433-453.

Banerjee, P. and Zhou, Y., 1995, Facilities layout design optimization with single loop material flow path configuration. International Journal of Production Research, 33, 183-203.

Bozer, Y. A., Meller, R. D. and Erlebacher, S. J., 1994, An improvement-type layout algorithm for single and multiple floor facilities. Management Science, 40, 918-932.

Francis, R. L, McGinnis, L F. and White, J. A., 1992, Facility Layout and Location: An Analytical Approach, 2nd edn (Englewood Cliffs, NJ: Prentice Hall), pp. 27-171.

Goetschalckx, M. 1992, An interactive layout heuristic based on hexagonal adjacency graphs. European Journal of Operational Research, 63, 304-321.

Heragu, S. S. and Kusiak, A., 1991, Efficient models for the facility layout problem. European Journal of Operational Research, 53, 1-13.

Koopmans, T. C. and Beckmann, M, 1957, Assignment problems and the location of economic activities. Econometrica, 25, 53-76.

Kusiak, A. and Heragu, S. S., 1987, The facility layout problem. European Journal of Operational Research, 29, 229-251.

LACKSONEN, T., 1994, Integrating material flow into a concurrent engineering framework. Proceedings of the 1994 International Material Handling Research Colloquium, Grand Rapids, MI, pp. 235-248.

LeE, R. C. and MboRe, J. M, 1967, CORELAP-computerized relationship layout planning. Journal of Industrial Engineering, 18, 195-200.

Liggett, R. S. and MitchelL, W. J., 1981, Optimal space planning in practice. Computer Aided Design, 13, 277-288.

Mecklenburgh, J. C., 1985, Process Plant Layout (New York: Longman). 
MeLLeR, R. D. and GAU, K. Y., 1996, The facility layout problem: recent and emerging trends and perspectives. Journal of Manufacturing Systems, 15, 351-366.

MonTREuIL, B., 1990, A modelling framework for integrating layout design and flow network design. In Proceedings of the Material Handling Research Colloquium, Hebron, KY, pp. 43-58.

Montreuil, B., Lefrancois, P., Marcotte, S. and Venkatadri, U., 1993, Holographic layout of manufacturing systems operating in highly volatile environments. Working Document 93-53, Groupe de Recherche en Gestion de la Logistique, Universite Laval, Quebec, Canada.

Nugent, C. E., Vollmann, T. E. and Ruml, J., 1968, An experimental comparison of techniques for the assignment of facilities to locations. Operations Research, 16, 150-173.

Seehof, J. M and Evans, W. O., 1967, Automated layout design program. Journal of Industrial Engineering, 18, 690-695.

Tompkins, J. A., White, J. A., Bozer, Y. A., Frazelle, E. H., Tanchoco, J. M. A. and Trevino, J., 1996, Facilities Planning, 2nd edn (New York: Wiley), pp. 286-381. 